\title{
Geothermal Produced Fluids: Characteristics, Treatment Technologies, and Management Options
}

\author{
Molly Finster $^{\mathrm{a}, *}$, Corrie Clark ${ }^{\mathrm{b}}$, Jenna Schroeder $^{\mathrm{b}}$, and Louis Martino ${ }^{\mathrm{b}}$ \\ ${ }^{a}$ Risk and Infrastructure Science Center (RISC), Global Security Sciences Division (GSS), \\ Argonne National Laboratory, 9700 S. Cass Ave, Lemont, IL, USA 60439 \\ ${ }^{\mathrm{b}}$ Environmental Science Division (EVS), Argonne National Laboratory, 955 L'Enfant Plaza SW, \\ Suite 6000, Washington, DC, USA 20024
}

\begin{abstract}
Geothermal power plants use geothermal fluids as a resource and create waste residuals as part of the power generation process. Both the geofluid resource and waste stream are considered produced fluids. The chemical and physical nature of produced fluids can have a major impact on the geothermal power industry and influence the feasibility of power development, exploration approaches, plant design, operating practices, and reuse/disposal of residuals. In general, produced fluids include anything that comes out of a geothermal field and must subsequently be managed on the surface. These fluids vary greatly, depending on the reservoir being harnessed, plant design, and life cycle stage in which the fluid exists, but generally include water and fluids used to drill wells, fluids used to stimulate wells in enhanced geothermal systems, and makeup and/or cooling water used during operation of a power plant. Additional geothermal-related produced fluids include many substances that are similar to waste streams from the oil and gas industry, such as scale, flash tank solids, precipitated solids from brine treatment, hydrogen sulfide, and cooling-tower-related waste.

This review paper aims to provide baseline knowledge on specific technologies and technology areas associated with geothermal power production. Specifically, this research focused on management techniques related to fluids produced and used during the operational stage of a power plant, the vast majority of which are employed in the generation of electricity. The general characteristics of produced fluids are discussed. Constituents of interest that tend to drive the selection of treatment technologies are described, including total dissolved solids, noncondensable gases, scale, corrosion, silicon dioxide, metal sulfides, calcium carbonate, metals, and naturally occurring radioactive material. Management options for produced fluids that require additional treatment for these constituents are also discussed, including surface

\footnotetext{
Abbreviations: AGGD, Argonne Geothermal Geochemical Database; BPJ, best professional judgment; CFR, Code of Federal Regulations; CWA, Clean Water Act; DCMD, direct contact membrane distillation; EGSs, enhanced geothermal systems; ELGs, effluent limitations guidelines; EMD, electrolytic manganese dioxide; GHG, greenhouse gas; HP, high-pressure; kg, kilogram(s); L, liter(s); mg, milligram(s); MSF, multi-stage flash; MED, multiple effect distillation; MWe, megawatt electrical; NCGs, noncondensable gases; $\mathrm{NF}$, nanofiltration; $\mathrm{NH}_{3}$, ammonia; NORM, naturally occurring radioactive material; NPDES, National Pollutant Discharge Elimination System; ppm, parts per million; RO, reverse osmosis; TDS, total dissolved solids; TENORM, technically enhanced naturally occurring radioactive material.

* Corresponding author. Tel.: +1 630252 9958; fax: +1 630252 46; E-mail address: mfinster@anl.gov.
} 
disposal; reuse/recycle; agricultural, industrial, and domestic uses; mineral extraction and recovery; and solid waste handling.

Keywords: geothermal; geothermal power plant; produced fluids; management techniques; beneficial reuse; recycling

\section{Introduction}

"Produced fluids," in the context of this paper, encompass the variety of fluids produced on-site during the various stages of geothermal energy exploration, field development, and power plant operations. Broadly, the term produced fluids includes any fluid that comes out of a well and subsequently must be managed on the surface. These fluids vary greatly, depending on the life cycle stage in which the fluid exists, but generally include water and fluids used to drill geothermal wells, fluids used to stimulate wells in enhanced geothermal systems (EGSs), and makeup and/or cooling water used during operation of a geothermal power plant. Additional geothermal-related produced fluids include many substances that are similar to exempt wastes (i.e., under Title 40, Part 261.4(b)(5) of the Code of Federal Regulations [40 CFR 261.4(b)(5)]) from the oil and gas exploration and production industry, such as scale, flash tank solids, precipitated solids from brine treatment, hydrogen sulfide, and cooling-tower-related waste. However, geothermal hazardous wastes (e.g., lubricants, hydraulic fluids, solvents, paints, and sanitary wastes) are not considered produced fluids for the purposes of this paper and are not discussed further.

The characterization of produced fluids is critical in determining appropriate management approaches, including consideration of specialized handling and potential environmental implications. This paper specifically focuses on some of the management techniques related to fluids produced and used during the operational stage of a geothermal power plant, the vast majority of which are employed in the generation of electricity.

\section{General Characteristics of Operational Produced Fluids}

The fluid that is extracted from the geothermal resource is commonly referred to as the geofluid. Geofluid is produced from a geothermal reservoir and directed into the power plant. Following the extraction of heat for the production of electric power, some fraction of the geofluid is then reinjected into the rock formation. At some geothermal power plants, other fluids associated with operation (e.g., condensate and cooling water blowdown) are injected along with the geofluid [1]. Any uncondensed vapor escapes from the cooling tower. In selected systems, the geofluid may also be reused as a working fluid to manage dissolved solids and minimize scaling [2].

The chemical composition of geofluids varies widely between and within geothermal fields, and in some cases, over time within the same geothermal well [2]. The exact chemical makeup of the geofluid can have significant implications for both the design and operation of a geothermal plant and its potential environmental impact. The chemical characteristics of geofluids were 
compiled in 2010 into the Argonne Geothermal Geochemical Database (AGGD) [2], which is available in the Geothermal Data Repository (http://gdr.openei.org) and was expanded upon in follow-up research focusing on EGSs [3]. For the composition analysis, $90^{\circ} \mathrm{C}$ was considered the cutoff temperature for being identified as a geothermal source. The $\mathrm{pH}$ values for the AGGD data appeared to be roughly normally distributed around a median of 7.3, with the majority of values falling between 5 and 10 . The full $\mathrm{pH}$ range was found to vary from as low as 0.9 to as high as 11.8, illustrating the broad range of characteristics common among geofluids. The most common chemical constituents reported for geothermal samples from the AGGD are presented as box-and-whisker plots in Figure 1 [2]. The data indicate that the major constituents include sodium $(\mathrm{Na})$, chloride $(\mathrm{Cl})$, bicarbonate $\left(\mathrm{HCO}_{3}\right)$, sulfate $\left(\mathrm{SO}_{4}{ }^{2-}\right)$, silica $\left(\mathrm{SiO}_{2}\right)$, calcium $(\mathrm{Ca})$, and potassium (K). However, the data also illustrate that the concentration of any chemical constituent can vary by around one to nearly six orders of magnitude between the 25th and 75th percentile (represented by the boxes) and by at least two to more than nine orders of magnitude across the extremes of the distribution (represented by the extended whisker lines on either side of the boxes).

\section{Treatment Technologies for Operational Constituents of Interest}

Although there is wide variability in geofluid chemical constituents, several constituents of interest can potentially affect geothermal power plant operations. These include total dissolved solids (TDS), noncondensable gases (NCGs), constituents associated with scale and corrosion, heavy metals, and naturally occurring radioactive material (NORM). These constituents, along with selected treatment options for mitigation (if deemed necessary) in operational produced water, are specifically discussed in further detail in Sections 3.1 through 3.4.

\subsection{Total dissolved solids}

TDS are a measure of the total ions in solution. In many instances, the term TDS is used to reflect salinity, since these ions are typically in the form of salts. In general, sodium chloride $(\mathrm{NaCl})$ is the predominant dissolved solid in most geofluids, followed by bicarbonate, sulfate, silica, calcium, and potassium [2]. Research identified the mean and median TDS values for high-temperature geofluids $\left(>150^{\circ} \mathrm{C}\right)$ to be approximately $81,000 \mathrm{mg} / \mathrm{L}$ and 2,500 mg/L, respectively; for moderate-temperature fluids $\left(90-150^{\circ} \mathrm{C}\right)$, these values were around 8,200 $\mathrm{mg} / \mathrm{L}$ and $1,100 \mathrm{mg} / \mathrm{L}$, respectively. However, the majority of TDS measurements were clustered between 500 and 5,000 mg/L, although some reservoirs had values outside this range [2,3]. For example, on the lower end, the Soultz-sous-Forêts EGS reservoir reported TDS readings of $95 \mathrm{mg} / \mathrm{L}$ [4], and the Geysers in California reported ranges from 130 to $340 \mathrm{mg} / \mathrm{L}$ [5]. At the higher end, the EGS project at Desert Peak in Nevada reported a geofluid TDS value of 7,000 parts per million (ppm) [6], and the Hudson Ranch I and II Geothermal Projects in California have average estimated brine concentrations of around 260,000 to 280,000 mg/L TDS $[7,8]$. 
In general, there are two major categories of desalination technologies: thermal methods and membrane processes. The basic principle of thermal distillation involves heating a saline solution to generate water vapor, which is then condensed on a cool surface to produce a liquid water containing very little of the original salt content. The major commercially developed thermal distillation processes are multi-stage flash (MSF), multiple effect distillation (MED), and vapor compression. Each of these methods is considered a mature and robust technology [9]. Currently, thermal distillation processes make up about $31 \%$ of the online desalination capacity worldwide.

Membranes are designed to selectively permit or prohibit the passage of certain ions, including salts, utilizing the natural processes of dialysis and osmosis. Commercially available membrane processes include reverse osmosis (RO), electrodialysis, and electrodialysis reversal. In the United States, RO membrane processes, often in combination with microfiltration, ultrafiltration, and/or nanofiltration (NF), have emerged as the predominant technologies used in desalination operations, as they are significantly less energy-intensive than traditional thermal techniques $[9,10]$. Currently, membrane processes account for approximately $66 \%$ of the online capacity for desalination worldwide. It is noted that water can be desalted through many other processes, including small-scale ion-exchange resins, forward osmosis, and hybrid processes; however, none of these technologies have achieved the commercial success of membranes or thermal distillation [9]. Together, these other desalination processes account for only about $1 \%$ of total desalination capacity worldwide.

The concentration of TDS is a key parameter determining the feasibility of a number of water treatment technologies. In general, treatment becomes more difficult and expensive as TDS increases. Table 1 lists some of the most common treatment technologies designed to remove salts and other inorganics from produced fluids, along with key advantages and disadvantages to using each specific technology $[9,10,11]$.

\subsection{Noncondensable gases}

All geofluids contain a fraction of NCGs, which either are dissolved or exist as gaseous components. These gases are released when steam is flashed, but do not condense at the normal condensing temperature of steam. As a result, they collect in the condenser of flash and steam systems, raising the back-pressure on the turbine exhaust (thereby lowering power output) unless they are pumped out. The release of NCGs does not occur in binary systems because the gases remain dissolved in the pressurized geofluid and are reinjected into the reservoir. In the case of an EGS, experience and data are limited, but it is expected that NCG volumes will be highly dependent upon the energy conversion approach taken (i.e., binary vs. flash), properties of the reservoir, and rate at which fluid is circulated in the system [2].

Commonly encountered NCGs include nitrogen $\left(\mathrm{N}_{2}\right)$, carbon dioxide $\left(\mathrm{CO}_{2}\right)$, hydrogen sulfide $\left(\mathrm{H}_{2} \mathrm{~S}\right)$, methane $\left(\mathrm{CH}_{4}\right)$, argon $(\mathrm{Ar})$, and oxygen $\left(\mathrm{O}_{2}\right)$. Typical $\mathrm{NCG}$ concentrations range from $0.5 \%$ to $1.0 \%$ of the steam generated [12], although NCG concentrations have been observed at the Geysers geothermal field to range from $0.2 \%$ to $1.8 \%$ of the steam produced [13]. 
These gases are usually released into the atmosphere, except for hydrogen sulfide, which must be scrubbed prior to release. However, increasing concerns over greenhouse gas (GHG) emissions may require limiting certain emissions in the future. For example, in the case of carbon dioxide, the compression and reinjection of the NCGs into the reservoir with the spent geofluid is an option for limiting emissions from resources with higher carbon dioxide concentrations. However, this process would result in additional parasitic power consumption [14]. Targeting reservoirs with lower carbon dioxide concentrations is another option for limiting these emissions [2].

For hydrogen sulfide abatement, some of the more common methods include caustic scrubbing followed by oxidation, adsorption, and catalytic conversion to elemental sulfur [15]. However, this gas could be separated and collected for use on-site or sold in the market as an additional energy and revenue stream [2]. For example, the hydrogen sulfide in vent gas could be utilized to generate sulfurous acid $\left(\mathrm{H}_{2} \mathrm{SO}_{3}\right)$ and/or sulfuric acid $\left(\mathrm{H}_{2} \mathrm{SO}_{4}\right)$ for use in $\mathrm{pH}$ modification processes and acidizing activities. In the field, a pilot burner-scrubber [16] and sulfur-oxidizing bacteria bioreactor [17] have been tested for this application. In a similar process, hydrogen sulfide in vent gas can be fed through a bed of halogen-containing oxidizingagent granules to yield elemental sulfur and a hydrogen halide gas (e.g., hydrochloric acid $[\mathrm{HCl}])$. The elemental sulfur and the produced hydrogen halide gas can be sparged into the brine, steam condensate, or water. The resulting inorganic acid solution can then be used to restore productivity (i.e., decrease brine $\mathrm{pH}$ for the control of silica, carbonate, or metal sulfide scale) and stimulate the wells [15]. Use of hydrochloric acid to reduce NCG surging (i.e., spikes in NCG flow that can result in reduced production or shut-down) can result in a sufficient decrease in the surges to allow longer or continuous operation of that well [18]. Table 2 lists some of the common treatment technologies for addressing NCGs in produced fluids, along with key advantages and disadvantages to using each specific technology.

\subsection{Scale and corrosion}

Scale and corrosion processes are directly related to the characteristics of a geofluid. Scale results from solids in the geofluid precipitating out and attaching to the surfaces of pipes and equipment, whereas corrosion results from chemical interaction between the geofluid and the internal surfaces of process equipment, including but not limited to well casing, pipes, and heat exchangers [2]. Failure to properly manage scale and corrosion can result in fouling of equipment and lead to significant reductions in fluid production rates, through-plant flow rates, heat transfer efficiencies, and injection rates [2,19,20,21], although in some cases, scale can actually form a protective coating inside pipes, which in turn may help to inhibit corrosion [22].

Periodic and often costly shutdowns of wells and surface facilities may be required for scale removal and corrosion control services. Scale inhibition and corrosion control methods employed in geothermal fields have generally been specific to brine chemistry and process conditions. Corrosion can usually be managed through materials selection during the plant design process, such as lining equipment with corrosion-resistant coatings or using corrosionresistant alloys [2]. 
Scale control programs typically involve the use of chemical inhibitors that retard overall rates of formation, such that the fluid moves beyond scale-sensitive plant facilities before scale precipitates [20]. Some of the methods that have been used to prevent and treat scaling in geothermal wells include varying pressure, changing the temperature profile, altering brine $\mathrm{pH}$, seeding, and using scale inhibitors. Since the use of acidification to mitigate scale formation, may actually result in increased corrosion, there is interest in non-acid additives for scale control $[2,21]$.

The three most common species of scale in geothermal systems are silicon dioxide (silica), metal sulfides, and calcium carbonate (calcite) [23]. These different forms of scale typically impact different stages of the process, with sulfides and calcium carbonate usually precipitating early and silica precipitating later in the process, after the geofluid is concentrated through flashing or heat is removed in the heat exchangers [2]. Other minerals have also been known to contribute to scaling, including barite and fluorite [22]. In general, most effort spent on controlling scale is targeted at calcite and silica because their constituents are usually found in much higher concentrations in geothermal brines [2]. The formation mechanisms and most commonly employed treatment options available for mitigating corrosion and metal sulfide, silica, and calcium carbonate scale from geothermal produced fluids are summarized in Table 3.

\subsubsection{Silicon dioxide}

Silicon dioxide, or silica, scaling is of greatest concern to most geothermal facilities because silica is found in virtually all geothermal brine.. In a reservoir, dissolved silica exists in solution in equilibrium with crystalline quartz as discrete silicic acid molecules $\left(\mathrm{H}_{4} \mathrm{SiO}_{4}\right)$, and its concentration is directly proportional to the temperature of the brine. As brine flows through the well to the surface, the temperature decreases and the silica solubility decreases correspondingly. During energy production, the pressure is dropped in the flash vessel, steam flashes, and the temperature of the brine decreases further, concentrating the brine and making the silica even more unstable. Under these conditions, the excess silicic acid does not normally re-precipitate as quartz, but instead precipitates as either amorphous silica or as co-precipitated iron $(\mathrm{Fe})$, magnesium $(\mathrm{Mg})$, calcium, and zinc $(\mathrm{Zn})$ silica deposits $[19,24]$. These deposits are extremely tenacious and can occur throughout the production field, plant, and injection systems. It has been suggested that controlling silica scale may actually reduce overall scaling, because the silica scale can act as a substrate or nucleation site for the formation of other types of scale [22].

In general, silica scale precipitation is a multi-step process, involving a nucleation-related induction period, aqueous polymerization, condensation of polymers to form colloids, and deposition onto a solid surface. Many chemical and physical variables, (e.g., solubility and kinetics) influence the rates of these steps [20]. Some common methods identified [25,26] and previously employed to mitigate and control silica scaling in geothermal systems include the following: 
- Maintenance of brine flash pressures and temperatures to prevent silica oversaturation;

- Exchange of brine heat to another working fluid without flashing (binary system operations);

- Dilution with steam condensate or non-saline water;

- Adjustment of brine pH (e.g., decrease with acid or acid gases);

- Controlled precipitation of silica by cationic surfactants or metals;

- Aging, evaporation/percolation, or pond retention;

- Reducing-agent treatment;

- Crystallization/clarification;

- Dispersants and polymeric organic inhibitors; and

- Chelating agents, organic acids, sequestrants and complexing agents.

3.3.1.1. Modification of operating conditions to minimize silica precipitation. Maintaining brine flash pressures and temperatures to keep silica in solution is one effective means of mitigating scale formation. It is usually easier to avoid scale formation in binary systems because only the temperature is being decreased and there is no concentration of the brine through the loss of geofluid to steam [2]. For flash systems, other treatment techniques are typically required.

3.3.1.2. Modification of $p H$ for treating silica. The rate of polymerization and scale formation is strongly influenced by the $\mathrm{pH}$; thus, controlling $\mathrm{pH}$ can generally control silica scaling. At geothermal fields around the world today, $\mathrm{pH}$ modification processes appear to be the most common method researched and applied for controlling amorphous silica and silicate scale deposition. In general, for $\mathrm{pH}$ modification to be successful, the reactions responsible for scale deposition must be slowed for a time sufficient to allow brine to migrate deep into injection formations before significant polymerization occurs. Since the most rapid kinetics occur under conditions of near-neutral $\mathrm{pH}$ [2], it is not surprising that potential methods for controlling this type of scaling from geothermal brines and other aqueous solutions include treatment with acid or base. Increasing the $\mathrm{pH}$ of brine, although possible, is not currently practiced in any geothermal power plant [24], owing to potential by-product formation of metal carbonates and hydroxides, which would also require mitigation or controlled precipitation [26]. Thus, matrix acidizing is more commonly utilized to control scale deposition and extend brine injection well life.

Research has shown that lowering $\mathrm{pH}$ both increases the induction time prior to the polymerization stage and decreases the polymerization rate [20]. This chemical treatment involves the injection of a reactive fluid (e.g., acid), typically downwell, into the porous medium at a pressure below the fracturing pressure. The acid works by dissolving material deposited in some of the porous formations, such as carbonates, metal oxides, sulfates, sulfides or chlorides, amorphous silica, drilling mud, and cement filtrates [27]. Adjustment of $\mathrm{pH}$ can also be done at the power plant. For example, in a multi-flash power plant, the high-pressure (HP) separation pressure is chosen to be above the silica saturation temperature; thus, the acid is added before any further pressure reduction [24]. 
Acids commonly employed in $\mathrm{pH}$ modification technology include hydrochloric acid, sulfuric acid, and sulfurous acid. Acid selection is dependent on compatibility with brine $[15,25,28]$. Hydrochloric acid is compatible with most geothermal brines. Sulfuric and sulfurous acids may not be compatible with brines containing significant alkaline-earth metals, because byproduct sulfate scale deposition could occur.

Typically, acid dosages are low and brine $\mathrm{pH}$ is decreased by less than 2 units (e.g., to a 5-6 $\mathrm{pH}$ range) to achieve good scale inhibition results and slow the kinetics of silica polymerization without substantially increasing corrosion $[24,25,29,30]$. The presence of natural chemical buffers (e.g., bicarbonate ion) can moderate the $\mathrm{pH}$ effect $[20,24]$. Thus, geothermal reservoir-specific silica scaling rate prediction models and brine titration data are often employed to select target acid dosages and $\mathrm{pH}$ levels.

In some $\mathrm{pH}$ modification applications, if acid dosages are small (e.g., tens of ppm), direct acid injection into brine may be feasible [26]. On the other hand, when the acid dosing requirement to achieve the target $\mathrm{pH}$ is significant, pre-dilution with hot, non-aerated brine is advantageous [26]. A standard acid treatment for wells scaled with amorphous silica during their commercial operation has generally included a pre- and post-flush with $10 \%$ hydrochloric acid and a main flush with a $10 \%$ hydrochloric acid-5\% hydrofluoric acid (HF) combination $[27,31,32]$. The hydrochloric acid pre-flush can also be used to dissolve carbonate minerals in the formation [32].

The $\mathrm{pH}$ reduction technology offers several advantages in that it is a cost-effective approach with reduced waste disposal requirements and opportunities for continued improvements [26]. In addition, it may be used in combination with other scale control methods, such as non-pH-adjusting chemical additives, reducing-agent treatment, or induced precipitation through seeding with silicate particles (discussed in further detail in Section 3.3.1.3). The uncertainties or limitations in the use of acidizing treatments are generally based on the following concerns: significant corrosion rates with the mineral acids at the temperatures encountered in geothermal wells; possible interference with surface processes; and placement problems resulting from long well-completion intervals [18].

\subsubsection{Non-pH-adjustment treatment options for silica. Overall, the most promising group of} non-pH-adjusting compounds arising from research to date is cationic nitrogen-containing compounds [21]. Four chemicals specifically identified for use as non-pH-adjusting additives, which would probably be most effective in combination with a $\mathrm{pH}$ adjustor (such as hydrochloric acid), are Corcat P-18 (polyethylene imine), Q PAE-HCl (polyaminoethylene hydrochloride), Ethoquad 18/25 (polyoxyethylene octadecylammonium chloride), and Mirapol A-15 (polydiquaternary ammonium chloride) [21]. Cations can also be used to induce massive polymerization and flocculation, with visible precipitates forming immediately after treatment [33].

Treatment of brines with reducing agents can also inhibit ferric and manganic silicates. Ferrous and manganous-rich amorphous silicas exhibit a higher solubility in aqueous solution than their higher-oxidation-state counterparts [26]. A preferred reducing agent is formic acid 
$(\mathrm{HCOOH})$, because it is strong enough to acidify brines at reasonable dosages, and the byproduct of reaction is benign carbon dioxide. Oxygen scavengers are also acceptable reducing agents in this application. Precautions should be taken to ensure that by-products of oxygen scavenging and metal ion reduction agents are compatible with other brine constituents. The reducing agents are known to precipitate silver, gold, antimony, and arsenic by a cementation reaction from geothermal brines, which may or may not be desirable [26,34].

An alternative method of controlling silica scale is to induce precipitation of silica from the brine in the flashing stage by contacting the flashed brine with silica or silica-rich seed crystals $[12,33,35,36]$. Preferably, the seed crystals are introduced into the high-pressure flashing vessel, which may then be referred to as a high-pressure flash crystallizer. When the silica saturation level in the brine is exceeded, the silica leaving solution will tend to preferentially deposit onto the seed crystals. The crystallization process, while starting in the high-pressure flash crystallizer, continues in successive, lower-pressure flashing vessels in which the brine typically again becomes supersaturated with silica. This approach results in the majority of the supersaturated silica precipitating onto the seed crystals instead of precipitating as scale onto vessel or equipment walls, or in injection wells. In a downstream reactor-clarifier, the silicious precipitate is separated from the brine as a slurry, which can contain about $30 \%$ by weight of silica [35].

Other research has suggested that aging geothermal power plant wastewater in a retention tank, which allows the monomeric silica in excess of amorphous silica solubility to form polymers, can also considerably lower the silica scaling potential of such waters. The size of a retention tank is determined by the rate of silica polymerization. If the wastewater has a $\mathrm{pH}$ between 7 and 8, the polymerization time is at a maximum, requiring the smallest retention tank; a $\mathrm{pH}$ lower than 6 at $80^{\circ} \mathrm{C}$ retards polymerization rates, thus requiring a larger retention tank [37]. However, increasing the rate of silica polymerization without a collection/removal unit process can increase the rate of silica deposition and risk of scaling, so the method is not likely to be suitable for geothermal produced waters of high salinity [37].

\subsubsection{Metal sulfides}

Metal sulfide scale formation is more complex and less understood than the other two forms of scale. A wide range of metals will precipitate as sulfides with different solubilities. In order of increasing solubility, these include mercury $(\mathrm{Hg})$, copper $(\mathrm{Cu})$, lead $(\mathrm{Pb})$, silver $(\mathrm{Ag})$, iron (Fe), and $\mathrm{Zn}[38]$. Sulfides of arsenic (As) (e.g., orpiment $\left[\mathrm{As}_{2} \mathrm{~S}_{3}\right]$ ) and antimony (Sb) (e.g., stibnite $\left.\left[\mathrm{Sb}_{2} \mathrm{~S}_{3}\right]\right)$ have also been observed $[22,24]$.

Some of the metallic sulfides tend to deposit near the wellbore, but most of these sulfides intermix with silicates and form a scale mixture [39]. Sulfide scale formation is known to increase not just with decreasing temperature and increasing $\mathrm{pH}$, but also under reduced (lowoxidation) conditions within the brine [2]. This is a particular problem in binary plants, as they often run at lower temperatures than flash plants and with retained gas in the process fluid. The deposition of metal sulfides can cause a reduction in heat transfer in the heat exchangers, which reduces the power output of the plant [24]. 
Current treatment options include mechanical removal, chemical dissolution with a caustic, or periodic dissolution by changing the on-line process $\mathrm{pH}$ conditions [24]. Partial oxidation of brine or combined oxidation and acidification have also been proposed as possible approaches for managing sulfide precipitation [38]. Alternatively, it has been suggested that metal sulfate scales are strongly controlled by dissolved hydrogen sulfate concentrations and are triggered by the release of gas from solution at the flash point $[2,40]$. Research is ongoing to try to develop an organic anti-scalant that can inhibit deposition, particularly for stibnite [24]. Table 3 summarizes geothermal scale formation mechanisms and mitigation options for metal sulfides from produced fluids.

\subsubsection{Calcium carbonate}

Calcium carbonate $\left(\mathrm{CaCO}_{3}\right)$, which has three known naturally occurring polymorphs (calcite, aragonite, and vaterite), is the most common scale in geothermal production systems utilizing low- and medium-temperature water. Unlike metal sulfides and silica, calcium carbonate increases in solubility as the temperature decreases; thus, the possibility of precipitation declines as energy is removed from the geofluid [2]. The major driver of calcium carbonate scale formation is related to the concentration of dissolved carbon dioxide. The low $\mathrm{pH}$ of the fluids under reservoir conditions caused by the presence of carbon dioxide in solution keeps calcite scaling from occurring in the reservoir. As the geofluid is produced, carbon dioxide comes out of solution. This has two main influences on the likelihood of scale formation. First, with the removal of carbon dioxide, the $\mathrm{pH}$ increases, liquid volume decreases, and the solubility of various ions in solution changes, favoring the precipitation of calcium carbonate scale $[2,18,41]$. Second, the removal of carbon dioxide from solution drives the dissociation equilibrium toward the precipitate $[2,12]$.

Calcite is the most stable polymorph of calcium carbonate. The unique mechanism for calcite scaling presents a major challenge for geothermal engineering. In many cases, geofluids are allowed to flash within the wellbore at the natural flash horizon. If conditions are ripe for calcium carbonate scale formation (i.e., high calcium ion $\left[\mathrm{Ca}^{2+}\right]$ concentration and high dissolved carbon dioxide concentration), scale will begin to form and can result in a constriction within the wellbore, eventually choking off flow from the well [2]. In general, binary systems have fewer issues with this kind of scaling because fluid is pressurized above the flash point throughout the process [2]. However, calcite precipitates have been observed in some cases at locations where there is a pressure drop, such as across pumps [19,42]. It is hypothesized that pressure drops result in local evolution of carbon dioxide, which can temporarily create conditions conducive to scale formation $[2,19]$.

For EGSs, the presence of cations (e.g., $\mathrm{Ca}^{2+}$ ) in a geothermal reservoir can also be problematic. This is because the solubility of these cations decreases with increasing temperature; thus, they tend to precipitate out of solution as the groundwater is injected for stimulation, and the temperature of the stimulation fluid increases because of contact with the reservoir. The temperature increase, combined with the pressure drops that occur during 
stimulation, can result in significant scaling on geothermal power equipment, as well as scaling along the well and the fracture network that stimulation is meant to open and expand [3].

One method developed to prevent calcium carbonate scaling involves the use of scale inhibitors, typically specialized and proprietary polymers. With this method, the scale-control options include the following: limiting production so that the drop in pressure is not sufficient to induce precipitation; injecting trace concentration of inhibitors in the surface equipment; injecting trace concentrations of inhibitors downwell to pressurize the fluid above the flash point; and squeezing inhibitor into the formation so that the inhibitor will be released slowly when production begins $[2,12,43]$. In addition, the use of downhole pumps can prevent scaling within the wellbore. However, the thermodynamics of this method typically favor binary systems over flash systems $[2,12]$. Acidizing with hydrochloric acid has also been found to effectively remove damage from calcium carbonate scaling, in either the wellbore or the formation. Acidizing is more effective at removing scale after a mechanical wellbore cleanout, since the acid will have more contact with the formation [18]. Other research into treating wells damaged with calcite scaling used a main flush of 12\% hydrochloric acid-3\% hydrofluoric acid [27]. Table 3 summarizes geothermal scale formation mechanisms and mitigation options for calcium carbonate from produced fluids.

\subsubsection{Corrosion}

Corrosion results from chemical interactions between the geofluid and the internal surfaces of equipment, including, but not limited to, well casing, pipes, and heat exchangers. It is a complex process and is dependent upon geofluid temperature, $\mathrm{pH}$, salinity, chloride content, and concentration of dissolved gases (carbon dioxide, hydrogen sulfide, ammonia $\left[\mathrm{NH}_{3}\right]$, and oxygen). Corrosion is initially managed during the plant design phase through the selection and use of corrosion-resistant alloys or application of corrosion-resistant coatings suitable for use in geothermal fluids at high temperatures and in other hostile environments [44]. However, these materials are typically more costly than materials like carbon or lower-grade stainless steels. Since there is such wide variability in geofluids from location to location, it is recommended that materials be chosen only after testing them with the specific geofluid to be used [2].

Internal treatment methods for corrosion control during operations are dependent upon the group of corrosive species (e.g., hydrogen sulfide or oxygen) that must be reduced or removed from the system [44]. Dissolved acidic gases (e.g., hydrogen sulfide and carbon dioxide) can be removed by aeration, where air is bubbled through the water. However, this process has the disadvantage of adding oxygen to the system, which itself becomes a corrosive dissolved constituent. Chemical degasification for removal of oxygen would then be accomplished by the addition of sulfite $\left(\mathrm{SO}_{3}{ }^{-2}\right)$ or hydrazine $\left(\mathrm{N}_{2} \mathrm{H}_{4}\right)$ to reduce the oxygen. The treatment of brines with reducing agents has also been proven to decrease corrosion [26]. Table 3 summarizes corrosion formation mechanisms and mitigation options for geothermal produced fluids. 


\subsection{Metals}

As noted previously, at low $\mathrm{pH}$ and lower temperatures, and with hydrogen sulfide present, heavy metals (e.g., mercury, copper, lead, silver, iron, zinc, arsenic, and antimony) in brines can precipitate as sulfides. In addition, the silica in geofluids can react with available metal cations (e.g., iron, magnesium, calcium, and zinc) to form metal-silica deposits [19,24]. Other metal precipitation, in the form of copper-arsenide and silver-antimony scales, has been described in $\mathrm{pH}$-adjusted brines from the Salton Sea area [34]. Similar scales have also been observed in low-TDS brines where the reductive deposition occurs on freely corroding carbon steel. When these deposits are coherent, they protect the underlying steel, but when they are not coherent, recent experience has indicated that rapid localized corrosion can result [24]. Further formation damage may result from the invasion of suspended solid precipitates (primarily iron silicate particles) present in injection brine into the permeable sections of the reservoir [34].

One option described for precipitating heavy metals naturally present in geothermal brines involves adding a base, such as ammonia (preferred), sodium hydroxide, calcium hydroxide, sodium sulfide, or sodium polysulfide, to the silica removal process [35]. The added base increases the $\mathrm{pH}$ of the brine-base mixture (to between about 6.2 and 6.6) and reacts with at least some of the heavy metals naturally contained in the brine, notably iron and/or lead. Finely divided, relatively insoluble heavy metal compounds precipitate from the brine, forming seed material onto which the supersaturated amounts of silica deposit. When ammonia is used, the base process preferably includes a further combining of the brine-base mixture with a flocculating agent (e.g., cationic polymer) so as to enhance flocculation of the insoluble silicious material [35].

Another treatment used to polish brines and collect metal scale deposits at the surface (just prior to injection) consists of passing brine (with a $\mathrm{pH}$ of 5) through a conduit packed with coiled, galvanized poultry wire for a time sufficient to precipitate a significant amount of iron silicate and heavy metal scales thereon [34]. The wire packing serves to filter some silicious suspended solids from the brine, while simultaneously removing and recovering a small amount of silver, copper, antimony, and arsenic by a cementation reaction. Scale deposition is thus greatly reduced, and the useful life of injection wells appears to be extended [34].

Arsenic removal from spent geothermal fluids has also been specifically studied. One technique considered viable for removing traces of arsenic from a fluid is ozone $\left(\mathrm{O}_{3}\right)$ oxidation followed by iron coprecipitation or catalyzed photo-oxidation processes [45]. The photooxidation process consists of sparging air through the photo-adsorber-treated fluid, and then irradiating it with ultraviolet lamps or exposing it to sunlight to oxidize the arsenic ion $\mathrm{As}^{3+}$ to $\mathrm{As}^{5+}$ [46]. Residual arsenic in the precipitate may be slurry-injected into a water disposal well or fixed/stabilized for land disposal. Another arsenic treatment method involves using strong base anion-exchange resins that remove traces of arsenic in geothermal fluids, provided that the amorphous silica is decreased below its saturation point or the water is stabilized against silica scaling by acidification [46]. Chloride-rich water, which had been treated with lime $\left(\mathrm{CaOH}_{2}\right)$ and filtered to reduce amorphous silica to well below its saturation point, successfully regenerated the resin. The ion-exchange alternative to arsenic removal by oxidation/precipitation has proven 
successful in reducing the concentrations of this element to below the limits set for drinking water standards [46].

Electrocoagulation treatment is another method for arsenic removal from separated geothermal produced water [47]. Electrocoagulation is an electrochemical process that uses direct current to remove a wide range of contaminants from wastewater. In general, aluminum (Al) or iron can be utilized as sacrificial electrodes, such that the application of a voltage results in the release of charged ions. The ions subsequently hydrolyze to aluminum hydroxide or iron hydroxide, depending on the electrode material being used. The metal hydroxides agglomerate the colloidal and monomeric silica, and the solid mass also adsorbs arsenic. The floc can then be easily removed by any suitable separation technology [47].

Metallic mercury is also sometimes found in geothermal fluids. Mercury emissions are typically discharged as gaseous species $\left(\mathrm{Hg}^{0}\right)$ and reach the atmosphere with the NCG fraction [48].

\subsection{Naturally occurring radioactive material and barium sulfate}

For geothermal activities, NORM may be present in the geologic formations overlying geothermal resources and/or within the geothermal resources themselves. During production and processing, the technologies employed to obtain and use geothermal energy have significant potential to concentrate NORM in certain operational waste streams, including scale, produced fluids, contaminated equipment, and biofilm deposits. The presence of such technically enhanced NORM (also known as TENORM) in geothermal waste streams can be of particular concern because of potential issues related to worker exposure (i.e., to alpha radiation), specialized and costly waste disposal requirements, and the possibility of contamination resulting from disposal or repurposing of solids.

NORM in geothermal operations is caused by radium-226 and radium-228, which are daughter products of uranium-238 and thorium-232, respectively [49]. More specifically, radium is a chemical homolog of alkaline earth elements like barium and calcium, which are present in geofluids and have a tendency to form scale (e.g., barium sulfate $\left[\mathrm{BaSO}_{4}\right]$ ) in production and injection wells, transfer piping, and power production and pollution control equipment.

Correlations have been observed between scale development and radionuclide concentrations. For example, NORM has been found to be associated with barite in both sludge and scale, and the potential for barite scale to precipitate increases with reservoir temperature [49]. Furthermore, although the radium activity of barite scale was reported to differ widely, high radium activity ( $>200 \mathrm{pCi} / \mathrm{L}$ ) has been shown to occur only if the TDS content exceeds approximately 35,000 mg/L [49]. In another study, an increase in NORM was observed in parallel with increases in a plant's circulation volume, with the highest values found close to the reinjection point, where the temperature is lower [50].

Studies of this contamination issue have generally focused on methods to either dissolve or inhibit NORM deposition. In general, attempts to dissolve or leach NORM from sludges with either water or a variety of chemical solvents have not been particularly successful. Acids and 
bases were also found to be ineffective in dissolving NORM. Commercially available barium sulfate dissolvers (chelates and converters in basic solution) were somewhat successful in leaching about $25 \%$ of NORM and barium sulfate from sludge, but only under very rigorous reaction conditions (e.g., high temperatures, long leach times, and stirring) [36].

A variety of scale inhibitors (generally highly charged, polymeric organic compounds) have been used in the petroleum industry to successfully inhibit barite deposition in wells, piping, and produced water handling equipment. When barite is properly inhibited, NORM deposition is also expected to be mitigated. Inhibitors that have found application in control of barium sulfate scales include phosphonates, polyacrylates, and polymalates [36]. Unfortunately, there is much disagreement and poor understanding concerning the effectiveness of these inhibitors, optimum dosage requirements, and reaction mechanisms involved in these inhibition reactions $[36,41])$.

In general, these inhibitors impart charges on particles, resulting in the dispersion of solids. Inhibitors will generally increase the negative charge on the geothermal solids because of their anionic character, causing increased dispersion and poor settling (upsets) in clarifiers. In this regard, flocculants are injected into clarifiers to gather and settle suspended solids for polishing of injectate brines. Inhibitors that disperse the silicious precipitates are expected to deleteriously affect flocculated clarifier operation. Thus, a method is needed that prevents or inhibits radioactive geothermal scale/sludge from precipitating but does not interfere with crystallizer-clarifier operation and the action of the flocculants used to settle slowly precipitating silicate species [36].

The more promising inhibitors for barium sulfate and NORM contained phosphonate and acrylate functionality. Most of the inhibitors dispersed clarifier solids. To combat the adverse reaction of the inhibitors on the suspended solids, various flocculant formulations were also researched. Several mildly cationic flocculants were able to overcome the additional negative charge imparted on the suspended solids by the anionic, dispersing inhibitors. This latter result suggests that injection of an inhibitor upstream of the low-pressure crystallizer (just before NORM and barium sulfate begin to precipitate), coupled with injection of a cationic flocculant into the secondary clarifier, could achieve the objective of controlling NORM deposition without adversely affecting the silicate crystallization-clarification process [36].

\section{Management Options for Produced Fluids from Operational Activities}

Characteristics of produced fluids vary greatly, and no single treatment technology can be applied at all locations [11]. In general, the selection of a management option at a particular site will vary and will depend upon the following: 
- Chemical and physical properties of the water;

- Volume, duration, and rate of water generation;

- Desired end use or disposition of the water;

- Treatment and disposal options allowed by state and federal regulations;

- Technical and economic feasibility of any particular option, including transportation and logistics;

- Availability of suitable infrastructure for disposal;

- Willingness of companies to employ a particular technology or management option, including concerns about potential liability; and

- Costs involved in meeting the requirements and restrictions set by the regulatory agency.

Operators must manage produced fluids in a cost-effective manner that minimizes environmental impacts and complies with federal and state regulatory requirements. The primary management option currently used for produced fluids is reinjection back into the geothermal reservoir. Other management options, which generally require additional treatment of the produced fluids, include disposal to a nearby surface water body or evaporation pond; reuse or recycling for agricultural, industrial, and/or hydrological purposes; and treatment for the recovery of other valuable resources (e.g., minerals or fresh water). A summary of the alternative geothermal produced fluid management options (other than reinjection into a reservoir) are presented in Sections 4.1. through 4.3.

\subsection{Surface disposal}

Many types of industrial wastewater are discharged directly to streams, rivers, and other surface water bodies. For example, circa 2003, a power plant in Turkey (Kizildere) reportedly discharged around 7.4 million tons of wastewater per year to the Buyuk Menderes River [51]. However, discharging produced fluids directly from a site presents various challenges, including typically high levels of TDS (salinity) and other constituents that would require treatment for compliance with a range of water quality standards and regulations.

In the United States, the Clean Water Act (CWA) requires that all discharges of pollutants to surface waters be authorized by a permit issued by state agencies under the National Pollutant Discharge Elimination System (NPDES) program. In order to meet the goals and requirements of the CWA, NPDES permits must consider two types of effluent limits when identifying effluent limits for produced water discharges: technology-based and water-qualitybased. Since there are no effluent limitations guidelines (ELGs), geothermal energy operations permits are based on best professional judgment (BPJ) to identify technology-based limitations on a case-by-case basis [52].

Another potential on-site disposal option for geothermal brines involves storage, sedimentation, and/or evaporation followed by permanent land disposal in specially designed ponds $[11,53]$. This process would be particularly applicable to arid climates, taking advantage of natural conditions of humidity, sun, and wind. It would not be practicable in humid climates. For example, evaporation basins have been used extensively for the handling of geothermal brines in Imperial County, California. In 2011, a California Regional Water Quality Control 
Board (Colorado River Basin Region) issued an order to UNOCAL Corporation to address an 85-acre facility that had 65 acres of used and active evaporation ponds to manage geothermal brines [54]. As another example, the Cerro Prieto Geothermal Field in Mexicali, Mexico, handles about $88 \%$ of the residual brine production (5,600 tons/hour) in evaporation ponds, which cover an area of approximately 4,700 acres [55].

The practice of using evaporation ponds, however, has a number of drawbacks. First, ponds have large land requirements [11]. Second, the potential for water recycling is lost, resulting in turn in an increased water supply budget. Also, this process can take several years to complete before the sediment is sufficiently dense to allow blending and capping, so that open ponds become a hazard on-site [53]. Finally, there is the potential for future air quality issues and salt deposition problems [11].

\subsection{Reuse and recycle}

With the world entering an age of water shortages and arid farming land, it is increasingly important to find ways of recycling wastewater. Geothermal produced water can possibly be considered as a potential resource for industry and agriculture, as well as for drinking water supplies, which would displace demand on existing potable water supplies. However, it is important to note that diverting produced fluids for potable water use may impact the long-term sustainability of a geothermal reservoir, unless fluids are being replaced.

Currently, geothermal produced water and condensate is being successfully treated for beneficial, non-potable use applications, including agricultural, industrial, and other (e.g., vehicle washing, fire-fighting, and dust control on gravel roads) [11]. Although researchers have found that turning produced water into drinking water resource is technically feasible, it entails an understanding of both environmental and economic implications [46]. Thus, the reuse of produced waters as a potable water resource requires additional study.

Unit processes used for geothermal produced water treatment to meet water standards are highly dependent on the source constituents, but include desilication of the waters to produce marketable minerals; removal of dissolved solids by RO or evaporation; blending, augmentation, or dilution with fresh water; removal of arsenic by oxidation/precipitation; and removal of boron (B) by various methods, including ion exchange [46]. 


\subsubsection{Agricultural use}

Produced waters could be used agriculturally for irrigation and for livestock and wildlife watering [11]. These applications could be a great benefit, especially to arid areas, but the water may still need to be treated.

\subsubsection{Industrial use}

There may be opportunities for reusing produced fluids in drilling or stimulation efforts. The oil and gas industry can substitute produced water for freshwater supplies in making new drilling fluids or hydraulic fracturing fluids. To be successfully re-used, the water may need treatment to meet operational specifications. Treated waters can be transported to off-site locations or used at a new well close by, such that long-term water storage is avoided [11].

Cooling towers are an essential part of power-generating facilities and require large quantities of water for continuous operation. To meet the high water demands, cooling towers use makeup water from various sources, such as the sea, lakes, rivers, irrigation ditches, and groundwater. In some cases, this water is trucked or piped to the geothermal facility. The use of reclaimed and recycled water as a makeup water source eliminates much of this off-site transportation cost. However, treatment is often required, and the quality of the makeup water dictates the number of possible cycles in the cooling tower [56]. Another potential drawback is the large volumes needed, which could result in large collection and associated transportation costs, depending on the distance between extraction wells and power plants [11].

Currently, advanced membrane separation technologies are among the more promising technologies for treatment of cooling tower water. Pressure-driven membrane processes (i.e., RO and NF) have already been shown to be an effective method for producing high-quality water for reuse. RO and NF separation technologies remove dissolved impurities from water through the use of a semipermeable membrane. NF separation technologies primarily remove divalent ions (e.g., calcium, magnesium), whereas RO removal will remove divalent ions along with monovalent ions (e.g., sodium). Because of the potential for high energy requirements associated with RO, NF could be a more desirable process, as it is a much less energy-intensive process that will still produce high-quality water [56].

Major problems associated with the operation of RO and NF are membrane fouling and scaling. To reduce the occurrence or severity of fouling, the amount of contaminant loading to $\mathrm{RO} / \mathrm{NF}$ systems needs to be reduced. This is typically accomplished by pretreatment of the source water to remove suspended solids [56]. Treatments specifically designed to control microbiological fouling of heat exchangers and cooling towers, control the $\mathrm{pH}$ of the water for mitigation of concrete dissolution, and abate hydrogen sulfide gas emissions from the water to the atmosphere also help to minimize membrane fouling and scaling [57,58]. Alternatively, cooling tower basins can be coated with epoxy-resin to minimize biofouling and corrosion problems. 
Another option for treatment of cooling tower water is direct contact membrane distillation (DCMD). DCMD is a thermally driven separation process. The driving force for mass transfer in DCMD is the vapor pressure difference across the membrane, which is induced by the temperature difference. DCMD has the potential to be an ideal treatment method for highly saline, warm feeds from geothermal operations [56].

In the field, both NF and DCMD were found to be effective treatments for geothermal brines. However, because of the high turbidity and silt density index of the blowdown water, pretreatment was determined to be a necessary step. Pilot testing of the NF system showed that high-quality water can be produced at a high recovery rate $(60 \%)$. A small-scale pilot DCMD demonstration was able to operate with limited flux decline. However, implementation at full or pilot scale would require waste heat in order to be economically feasible; thus, it is believed that DCMD would be a logical and effective choice for treating superheated geothermal brines [56].

\subsubsection{Domestic use}

Some produced water has low salinity [59] and may be suitable for reuse with little or no treatment; however, this is not typically the case. Over the years, a number of researchers have attempted to produce fresh water either directly from geothermal brines or using geothermal energy as an energy source for desalination. For high-saline produced waters, thermal distillation processes can be used to produce very clean product water. The concentrated brine stream is hauled off-site for disposal at a commercial disposal facility, while the clean water can be reused [11]. However, even though this process has been proven to be a technically feasible option, particularly for communities in arid areas, attempts to produce fresh water have run into high operating costs $[2,11]$.

Another domestic use of geothermal fluids involves the heating of cold groundwater that is piped into a town's central heating system, as is currently being done at the Nesjavellir geothermal field in Reykjavik, Iceland [60,61]. The first step of treatment is to separate geothermal water and steam. The water and steam are piped separately to a powerhouse where electricity is generated by steam turbines. The excess water is partly disposed of in a shallow well in the nearby lava field and partly into on-site reinjection wells. The steam is condensed in a tubular condenser and cooled to approximately $55^{\circ} \mathrm{C}$ with cold groundwater, and then piped through heat exchangers to a final temperature of $87^{\circ} \mathrm{C}$, using $192^{\circ} \mathrm{C}$ geothermal water from the separators. By degassing under vacuum in the deaerators, the dissolved oxygen is removed from the heated water. The final treatment before the water is pumped for heating is to inject some geothermal steam, which acts to remove the last traces of dissolved oxygen (via reaction with the hydrogen sulfide in the steam) and adjust the water to $\mathrm{pH} 8.5$ [61]. 


\subsubsection{Hydrological use}

Reuse for hydrological purposes can include streamflow augmentation. Some interstate rivers are subject to compacts that require upstream states to provide a minimum flow level for the downstream states. In this case, the produced fluid is treated to allowable discharge standards to help augment declining water levels in streams [11].

The use of produced water in managed or constructed wetlands would provide a natural form of treatment. It would also have the added benefits associated with wetlands, including creation of a good habitat for wildlife. The downside of this option would be the large space requirements and need for extensive oversight and management [11]. Depending on the contaminants, the water also may require some degree of pretreatment prior to wetland application.

\subsection{Mineral extraction and recovery}

Geothermal fluids have had intimate and lengthy contact and interaction with the layers of the earth's crust that they flow through, resulting in dissolution of minerals and metals from the host rocks into the hot water [62]. Potential products present in geofluids include silica, zinc, lithium (Li), and precious metals. Some geofluid solutions can be rich in these materials, while some are relatively dilute [63]. In many cases, this mineral content may be considered more a nuisance than an asset. However, if produced fluid from a particular formation contains sufficient concentrations of desirable compounds, it can be a cost-effective feedstock for the extraction of these minerals as marketable by-products. As a result, in addition to energy production, geofluids have long been looked at as potential sources of other valuable resources, particularly minerals and metals.

In the early history of geothermal resource development, boric acid, sulfur, and ammonium salts were recovered commercially from geothermal brines, until they lost economic competitiveness to other mining processes [62]. Much effort was also historically focused on the production of potassium chloride for fertilizer production, carbon dioxide for industrial purposes, and a range of industrial metals (e.g., zinc, lead, iron, magnesium, lithium, silver, and manganese [Mn]). Other products whose recovery was attempted have included, but are not limited to, sodium chloride, calcium chloride $\left(\mathrm{CaCl}_{2}\right)$, and silica [2]. However, of these projects, very few were proven to be economically viable or had more than a temporary commercial success. Major challenges included changes in the market price of the product and high operating costs resulting from high temperatures, scale and corrosion, and challenging separation processes due to complex brine chemistry [2,64,65]. In addition, requirements for reinjection of spent brine to preserve the resource and minimize subsidence severely limit its use in many current geothermal systems [11].

In general, resource removal optimally takes place after or near the end of the energy extraction process, but prior to reinjection. Separation processes historically used or proposed for the extraction of aforementioned minerals and metals from geothermal brines primarily included evaporation and crystallization. Another option for dissolved species involves photoassisted 
oxidation followed by removal through precipitation/co-precipitation [45]. Other processes have included enrichment through RO and extraction using ion-exchange resins and functionalized carbon/silica aerogels [20]. It appears that systems that utilize selective ion exchange or similar processes may have the most potential in these cases. Modern materials engineering may allow for the development of cheaper and more selective ion-exchange resins that can better withstand the harsh conditions present in geofluids [2]. One of the general problems encountered in the extraction of metals from aqueous solutions involves changes in $\mathrm{pH}$ associated with the exchange of metal ions for hydrogen ions in ion-exchange reactions. This causes a progressive lowering of the $\mathrm{pH}$, which in turn impedes the efficiency of the process. Attempts to solve this problem have been reported, but their success has been limited [66].

A significant advantage of mineral extraction from geofluids, compared with other brines, is that much of the expensive and time-consuming well drilling and pumping is already done, thus lowering the bar for economic production. However, the economics of mineral extraction are driven by numerous factors, including geofluid chemistry; product quantity and quality; market price, size, and accessibility; recovery cost; and operational challenges (e.g., scale and corrosion) [2,64]. Thus, the potential for mineral extraction from extracted water will be highly site-specific. On the basis of past history, formations exist that have favorable conditions for mineral extraction from brines; however, these formations appear to be the exception rather than the rule [11].

Products with the greatest economic potential based upon this limited analysis are silver, potassium, lithium, manganese, silica, and zinc [2]. This list is consistent with the past history of geofluid mining. However, this history also shows that large economic potential does not in any way guarantee that the resource can be exploited profitably [2]. Most of the previous research in this field has focused on the extraction of silica, lithium, zinc, and manganese. Therefore, a more detailed review of these materials is provided in Sections 4.3.1 through 4.3.6, with other materials noted at the end.

\subsubsection{Silica}

The silica in geothermal fluids interferes with traditional extraction methods because of its tendency to cause equipment fouling. Thus, the removal of silica is a necessary precursor to extracting other valuable dissolved elements from geothermal fluids. Moreover, by purposefully precipitating silica as a high-surface-area, porous material, with properties similar to those of commercially precipitated silica, not only is the initial silica-scaling problem solved, but a marketable by-product is produced. Other benefits that may also be realized as a side effect of this process include additional energy extraction, which would not otherwise be economically efficient because of scaling and recycling of the low-TDS permeate for use in cooling processes [20,62]. In addition, researchers are evaluating whether silica can be used as a cement substitute in building blocks [67]. Salton Sea geofluid treatment residuals have been used as beneficial building materials in the past [36].

Many methods have been used to precipitate silica as a commercial-grade commodity from geothermal fluids. One common technique uses a RO separation unit to concentrate the 
brine and create a freshwater stream, which could be used for evaporative cooling [20,46,62,63]. The concentrated brine is then pumped into a reactor where an agglomerating agent or flocculant is added to enhance precipitation before the silica is extracted [20,21]. For example, the addition of a base (e.g., soda ash $\left[\mathrm{Na}_{2} \mathrm{CO}_{3}\right]$, lime, and hydroxides) that raises the $\mathrm{pH}$ (to $\mathrm{pH} 8.0 \pm 0.5$ ) can increase the buffering capacity of the fluid and enhance water desilication, resulting in undersaturation with respect to amorphous silica [46]. A salt (e.g., magnesium chloride) that dissolves into active cations or synthetic polymer electrolytes can also be added to a geofluid and used to increase polymerization rates and facilitate agglomeration of silica $[46,62]$. Silica particles can be removed from solution using filtration, settling, or centrifugation, depending on the particle size. Modern ultrafiltration membranes have been incorporated into the silica extraction processes [20,62].

Geothermal silica can be of very high purity, greater than 98 weight $\%$ for untreated silica, and about 99.6 weight $\%$ for acid-rinsed silica. These compositions compare favorably with commercial silica precipitates, which often have 1 to 5 weight $\%$ impurities. The precipitate does sometimes contain measurable arsenic; however, the arsenic is less enriched in the silica precipitate than in bulk fluid. The silicon (Si)-to-arsenic ratio (i.e., Si:As) of the fluid is about 800:70 in the silica precipitate. If necessary, a simple acid rinse could be used to reduce the arsenic levels by approximately two-thirds in the silica precipitate final product [20].

The silica-free concentrate can then be pumped through another process for extraction of other potentially valuable materials which have become enriched in the geofluid brine. Example extraction processes typically include the use of an ion-exchange reagent or other functionalized material (e.g., aerogels) [20,68]. These exchange recovery systems generally involve contacting the aqueous metal-containing solution with an exchange reagent that would be impregnated with the metal, which would subsequently be stripped to produce a more concentrated metalcontaining solution. The metal pregnant strip solution is of controllable composition or purity, and the metal can be directly recovered therefrom, normally by electrolysis [68]. The final waste fluid is eventually pumped to a surface pond and reinjected into the subsurface [63].

\subsubsection{Lithium}

The technology to extract lithium from produced water may be considered profitable in situations where brine lithium concentrations are sufficiently high. Generally, the lithium is either captured using ion-exchange resins or directly precipitated from the brine as lithium salts. For example, treatment with a combination of magnesium and iron can precipitate hectorite, which is a lithium-rich clay mineral of the montmorillonite group [46]. In practice, Californiabased Simbol Materials has begun operations to mine lithium from geothermal brine [69]. If present, zinc and manganese can also be recovered along with the lithium [63]. 


\subsubsection{Zinc}

Extraction of zinc from brine is usually performed through various combinations of ion exchange or solvent extraction and electrochemical stripping [66]. In general, these processes begin with the mixing of brine with an immiscible anionic organic solvent or ion-exchange bed that is selective for the extraction of zinc chloride [62,70]. The zinc chloride-loaded anionic extractant is eluted to produce an impure zinc chloride solution. Iron, arsenic, and lead are also extracted in the process, but they are subsequently removed by oxidation followed by solids removal. The zinc is then contacted with a cationic extractant that is also selective for zinc. After removal of the zinc-depleted aqueous phase, the zinc-loaded extractant is rinsed and then stripped with a sulfuric acid solution. Zinc is recovered as metallic zinc by conventional electrowinning $[62,70]$.

\subsubsection{Manganese}

Manganese is typically extracted in the form of electrolytic manganese dioxide (EMD). One of the most common processes being used for extracting manganese involves mixing the manganese-containing material with sulfuric acid to form a manganese sulfate electrolyte. This intermediate is then separated from other metals by precipitation and filtration. Thereafter, the manganese sulfate is subjected to solvent extraction and electrowinning [66]. Another method involves a liquid-liquid anoxic extraction of manganese (and iron) from brine, followed by oxidation to cause the iron to precipitate (for subsequent removal). Electrolysis of the chloride (or sulfate) liquor is then performed to extract the EMD, which is deposited on the cathode [66]. Other work has shown that a solvent extraction method utilizing diethylhexyl phosphoric acid and a quaternary amine shows good selectivity for manganese over other metals present in the brine [62].

\subsubsection{Sulfur}

Steam containing hydrogen sulfide can be purified to recover sulfur. This is done by passing the steam through a reactor packed with activated carbon in the presence of a stoichiometric amount of oxygen, which oxidizes the hydrogen sulfide to elemental sulfur that is adsorbed on the bed. After the sulfur has been recovered, the carbon can be recycled by vacuum distillation, inert gas entrainment, or solvent extraction. This process of purifying geothermal steam is very suitable if the steam contains other NCGs [63].

\subsubsection{Other by-products}

Geothermal fluids could be used to produce some inexpensive salts such as sodium chloride, sodium sulfate $\left(\mathrm{Na}_{2} \mathrm{SO}_{4}\right)$, calcium chloride, and others [62]. Although these materials are not of high economic value, they may be produced as by-products of the processes that produce other more valuable solids and may add to the profitability of geothermal co-production. Another potential by-product is high-surface-area precipitated calcium carbonate. This 
compound has unique properties that make it useful in applications such as paper filler, allowing it to command a much higher price than limestone [62,71]. Researchers in Brazil are also studying the economic feasibility of extracting soda ash from produced water $[11,72]$.

Precious metals such as gold $(\mathrm{Au})$ and silver are often contained in geothermal reservoirs. To extract these metals, a pregnant solution is pumped through activated charcoal, which absorbs gold and silver, at the process plant. Cyanide solution is pumped to a holding basin, where lime and cyanide are added to repeat the leaching process. The charcoal is chemically treated to release the precious metal and then reactivated by heating for future use. The resultant goldand/or silver-bearing strip solution, more concentrated than the original pregnant cyanide solution, is treated at the process plant to produce bars of impure metal [63].

Specialty chemicals, such as cesium (Cs) and rubidium $(\mathrm{Rb})$, can also be enriched in geothermal fluids and, because of their high value, could be extracted at a profit. These elements are used interchangeably in thermionics applications, such as oxygen getters (i.e., deposits of reactive material) in vacuum tubes and alloys used in photocells. The hydroxides of cesium and rubidium are the strongest known bases. Cesium and rubidium can be separated using high cross-linkage ion-exchange resins [62]. Novel methods utilizing crown ethers have also been investigated [71].

Boron in geothermal produced water is present as boric acid $\left(\mathrm{H}_{3} \mathrm{BO}_{3}\right)$ and its dissociated anion, borate. Special ion-exchange resins and borate-selective media have proven successful in removing boron from geothermal fluids $[46,71]$. Boron is recovered as borax at the Larderello, Italy, geothermal field at the rate of 12,000 tons/year, and iodine (I) and bromine (Br) are recovered from Cheleken thermal waters in Russia [73].

The production of clays is also a topic of research. In laboratory reactions, kerolite clay (a disordered form of talc) was precipitated upon treating synthetic and field waters with magnesium at $130^{\circ} \mathrm{C}$. In addition, under similar conditions, sodalite $\left(\mathrm{Na}_{4} \mathrm{Al}_{3} \mathrm{Si}_{3} \mathrm{O}_{12} \mathrm{Cl}\right)$ and Zeolite $\mathrm{P}$ (i.e., various forms of gismodine) were precipitated upon treatment with aluminum hydroxide or sodium aluminate $\left(\mathrm{NaAlO}_{2}\right)$ [46]. For kerolite production in the field, magnesium chloride $\left(\mathrm{MgCl}_{2}\right)$ is added at slightly above stoichiometric proportions $(3 \mathrm{Mg}: 4 \mathrm{Si})$, and the $\mathrm{pH}$ is increased to about 10.0 with caustic soda or lime. The crystallizer and clarifier include sludge recirculation to maximize the "seed crystal" effect, thus providing a high surface area for precipitation. After precipitation, the water is clarified, possibly treated further to meet industrial water specifications, cooled to pipeline specifications, and finally sent to a pipeline for transport to the industrial site. The kerolite sludge is dewatered using a filter and can be dried in a steamheated kiln or in an arid, but cool, environment at the power plant. Dried kerolite is transported off-site for commercial refining and use. For zeolite manufacture in the field, sodium aluminate is used as both the aluminum and base source. Hectorite or saponite (i.e., a magnesium-rich clay mineral of the montmorillonite group) is made in a similar fashion by treating water with salts (e.g., $\mathrm{Mg}^{2+}$ and $\mathrm{Fe}^{2+}$ ) and a base [46]. 


\section{Geothermal Operational Solid Wastes}

Extracting heat for the purposes of geothermal power generation can require the processing of significant volumes of geofluid. For example, generating $240 \mathrm{MWe}$ from a liquiddominated steam flash plant can involve the processing of more than $175,000 \mathrm{~m}^{3}$ of brine [73]. As discussed previously, this geothermal brine can be treated to recover some economically valuable products, but significant solid waste is also generated. For example, from a mass balance standpoint, approximately 3 million pounds per day of silica pass through the world's geothermal plants [62]. A significant amount of that silica flux must be removed as waste to preserve the commercial viability of the geothermal resource [62]. In addition, geofluid containing environmentally significant NCGs (e.g., hydrogen sulfide) must also be treated, resulting in the generation of additional large volumes of air pollution control-related waste.

The solid wastes generated by the geothermal power production industry can vary significantly from plant to plant and are typically disposed of off-site (e.g., in hazardous-waste landfill). Characteristics of a few power production-related waste streams are described by way of example.

At the Salton Sea geothermal complex, crystallizer/clarifiers are used to remove solids from processed geofluids prior to reinjection. Historically, it has been estimated that about 45 tons of sludge daily (or $600 \mathrm{mg}$ of sludge per $\mathrm{kg}$ of brine) was generated in this manner from the Salton Sea facilities [36]. Approximately $65 \%$ of this sludge was iron-rich silica, with fluorite and barite making up about $3 \%$ and $31 \%$ of the sludge, respectively. In addition, Salton Sea brine can also contain a number of environmentally significant inorganic constituents, which could also be present in the clarifier sludge. For example, arsenic, copper, and lead have been detected in the brine at concentrations of 12,5.5, and $91 \mathrm{mg} / \mathrm{kg}$, respectively [73]. Furthermore, in an effort to address the creation of NORM scale in the clarifiers, an inhibitor was subsequently introduced into the sludge-handling process. The inhibitor reduced the amount of NORM in the filter cake sludge and reduced generation of sludge by about $40 \%$ [36]. This dated information suggests that, at least at the time, the Salton Sea geothermal complex generated about 27 tons of solid waste per day as a result of geofluids treatment prior to reinjection.

The Cerro Prieto plant in Mexico reportedly generates up to 50,000 tons of silica waste yearly, which averages to nearly 140 tons daily [67]. This waste is composed of amorphous silicon dioxide, sodium chloride, potassium chloride, and oxides of calcium, sodium, potassium and titanium [74].

At the Geysers, abatement chemicals added to condensed steam used to operate

19 geothermal units result in the accumulation of significant amounts of pollution-control-related sludge. Approximately 160 to 570 tons of sludge containing around $12 \%$ to $20 \%$ solids are removed from a cooling tower during the blowdown cycle. No information is provided about the frequency of the blowdown cycle [75]. 


\section{Conclusions}

The wide variability in geochemistry of geothermal reservoirs and produced fluids can inherently present challenges to geothermal power plant operations and produced fluid management. Some of the additional challenges and research needs related to geothermal produced fluids that were identified during this research include the cost and consumption of water, energy consumption, GHG emissions, and waste management (i.e., land use and TENORM).

In general, geothermal energy is considered to be a sustainable and renewable energy source. However, it is important to consider that geothermal energy development typically involves the use of water during multiple stages of development, including exploration, operations, and maintenance activities. As a result, the cost of obtaining water and the sustainability and renewability of the resource are significant factors to consider in the economics of geothermal projects.

Another critical item to consider, especially in regard to treatment technologies, is energy consumption associated with treatment, which is typically dependent upon the specific technology, unit design, feedstock and product water quality, facility location, and concentrate disposal costs. In the research reviewed here, treatment techniques focus on TDS, NCGs, constituents associated with scale and corrosion, heavy metals, and NORM. Using TDS as an example, comparing the energy consumption of the most commonly used desalination processes (i.e., MSF, MED, and RO) reveals that the thermal methods require more energy than membrane processes. This is primarily because of the high energy need for water vaporization to run the MSF and MED processes and the fact that continuous improvement in RO technology has resulted in lower power consumption [76]. Additional treatment technologies that may be needed for beneficial reuse or recycle of produced fluids would add an incremental energy cost. Thus, when considering the potential for beneficial reuse or recycle of geothermal produced fluids, one should also recognize the importance of maintaining the long-term sustainability of a producing geothermal reservoir.

In addition, geothermal energy can involve the ongoing release of GHGs as part of the NCGs (as discussed in Section 3.2). That is, depending upon the design of the geothermal plant and the nature of the geothermal reservoir, both methane and carbon dioxide can be emitted from certain geothermal reservoirs. GHGs could result from the various treatment technologies employed, depending on the source of the energy used to power the processes. Growing concern over anthropogenic climate change and greenhouse gas emissions has spurred interest in the use of alternative energy sources for treatment; however, the types of available alternative energy sources vary greatly, depending on location and local conditions.

Finally, geothermal energy production can involve the production of potentially highvolume and/or chemically complicated waste streams. For example, surface land disposal options (e.g., evaporation ponds) can often take up a large footprint far in excess of the actual geothermal production facility. Alternately, if produced fluids are treated for reuse, the solid waste stream in particular can require the construction of engineered land disposal units, as well as efforts to preclude groundwater contamination and long-term legacy costs associated with the 
post-closure care of the disposal sites. Furthermore, some solid waste streams can include TENORM constituents that may potentially create a site worker hazard at the geothermal plant during production, waste management, and disposal operations. One management approach is to preclude the generation of TENORM by preventing scale from forming in the first place; another approach involves creating specialized flocking formulations that can be used to selectively flocculate the TENORM constituents from a given waste stream. Although research on TENORM is currently ongoing, some of the more significant research gaps identified in this review are associated with the generation and management of TENORM.

\section{Acknowledgments}

Argonne National Laboratory's work was supported by the U.S. Department of Energy, Assistant Secretary for Energy Efficiency and Renewable Energy, Geothermal Technologies Office, under contract DE-AC02-06CH11357. 


\section{References}

[1] EPA (U.S. Environmental Protection Agency). The class V underground injection control study volume 17: Electric power geothermal injection wells. EPA/816-R-99-014q; 2007.

[2] Clark CE, Harto CB, Sullivan JL, Wang MQ. Water use in the development and operation of geothermal power plants. ANL/EVS/R-10/5. Prepared for U.S. Department of Energy, Office of Energy Efficiency and Renewable Energy (EERE), Geothermal Technologies Program. Argonne, IL: Argonne National Laboratory; 2011.

[3] Clark CE, Harto CB, Schroeder JN, Martino LE, Horner RM. Life cycle water consumption and water resource assessment for utility-scale geothermal systems. ANL/EVS/R-12/8. Prepared for U.S. Department of Energy, EERE, Geothermal Technologies Program. Argonne, IL: Argonne National Laboratory; 2013.

[4] Scheiber J, Nitschke F, Seibt A, Genter A. Geochemical and mineralogical monitoring of the geothermal power plant in Soult-sous-Forêts. In: Proceedings, Thirty-seventh Workshop on Geothermal Reservoir Engineering, January 30-February 1, Stanford University, Stanford, CA; 2012.

[5] RMT, Inc. Calpine enhanced geothermal systems project: final environmental assessment. Prepared for U.S. Department of Energy. San Mateo, CA: RMT, Inc.; 2010.

[6] BLM (Bureau of Land Management). Desert Peak 2 geothermal project environmental assessment. Winnemucca, NV U.S. Department of the Interior, Winnemucca Field Office; 2003.

[7] CA RWQCB (California Regional Water Quality Control Board) Colorado River Basin Region. Waste discharge requirements for Hudson Ranch Power I LLC, Owner, Hudson Ranch I geothermal development project, proposed geothermal power plant, Salton Sea known geothermal resource area (KGRA) - Imperial County, order no. R7-2008-0063; 2008.

[8] CA RWQCB. Waste discharge requirements for Hudson Ranch Power II LLC, owner, Hudson Ranch Energy Services LLC, Operator, Hudson Ranch II geothermal project and power plant, Salton Sea KGRA — Imperial County, order no. R7-2013-0045, Colorado River Basin Region; 2013.

[9] NRC (National Research Council). Desalination: a national perspective. Washington, DC: National Research Council; 2008.

[10] DOE (U.S. Department of Energy). The water-energy nexus: challenges and opportunities. Water-Energy Technology Team, Office of Energy Policy and Systems Analysis (EPSA); 2014.

[11] Harto CB, Veil JA. Water management of water extracted from carbon sequestration projects. ANL/EVS/R-11/1. Prepared for U.S. Department of Energy, EERE, Geothermal Technologies Program. Argonne, IL: Argonne National Laboratory; 2011. 
[12] DiPippo R. Geothermal power plants: principles, applications, case studies and environmental impacts. 2nd ed., Butterworth-Heinemann, Elsevier; 2008.

[13] Goldsmith M. Geothermal resources in California: potentials and problems. Pasadena, CA: California Institute of Technology, Environmental Quality Laboratory; 1971.

[14] INL (Idaho National Laboratory). The future of geothermal energy: impact of enhanced geothermal systems (EGS) on the United States in the 21st century. Cambridge, MA: Massachusetts Institute of Technology; 2006.

[15] Gallup DL. Simultaneous hydrogen sulfide abatement and production of acid for scale control and well stimulation. In: Proceedings, International Geothermal Conference, Reykjavik, Iceland; 2003, p. 5.

[16] Gallup DL, Kitz K. On-site production and usage of sulfurous acid for scale inhibition. In: Proceedings, 19th Annual PNOC-EDC (Philippine National Oil Company - Energy Development Corporation) Geothermal Conference; 1998, p. 191-198.

[17] Takeuchi K, Fujioka Y, Hirowatari K, Kusaba S, Suzuki H. Scale prevention method by pH modification using advanced bioreactor. In: Proceedings, World Geothermal Congress 2000, May 28-June 10, Kyushu-Tohoku, Japan; 2000.

[18] Evanoff J, Yeager V, Spielman P. Stimulation and damage removal of calcium carbonate scaling in geothermal wells: a case study. In: Proceedings, World Geothermal Congress, May 18-May 31, Florence, Italy; 1995.

[19] Stapleton M. Scaling and corrosion in geothermal operation. Minden, NV: PowerChem Technology; 2002.

[20] Burton EA, Bourcier WL, Wallace A, Bruton CJ, Leif R. Silica scale management: Lowering operating costs through improved scale control, and adding value by extracting marketable by-products. GRC Transactions 2003; 27:519-522.

[21] Crane CH, Kenkeremath DC. Field evaluations of chemical additives for scale control. GRC Transactions $1981 ; 5: 459-462$.

[22] Harrar JE, Otto CH, Jr., Deutscher SB, Ryon RW, Tardiff GE. Studies of brine chemistry, precipitation of solids, and scale formation at the Salton Sea geothermal field. Livermore, CA: Lawrence Livermore National Laboratory; 1979.

[23] Phillips SL, Mathur AK, Doebler RE. A study of treatment methods for geothermal fluids. Presented at the SPE International Symposium on Oilfield and Geothermal Chemistry, June 27-29, University of California, San Diego, CA; 1977.

[24] Brown K, Lichti K. Some current challenges in production geochemistry. In: Proceedings, New Zealand Geothermal Workshop 2012, November 18-21; 2012. 
[25] Gallup DL. Brine pH modification scale control technology. GRC Transactions 1996; 20:749-755.

[26] Gallup, DL. pH modification scale control technology. In: Proceedings of the International Workshop on Mineral Scaling, May 25-27, Manila, Philippines; 2011.

[27] Flores-Armenta M, Ramirez-Montes M. Evaluation of acid treatments in Mexican geothermal fields. GRC Transactions 2010; 34:1135-1140.

[28] Kiyota Y, Hirowatari K, Tokita H, Haruguchi K, Uogata K. 2000. Evaluation on geothermal injection treatment by $\mathrm{pH}$ modification. In: Proceedings, World Geothermal Congress 2000; 2000, p. 3077-3082.

[29] Kiyota Y, Uchiyama N. Silica scale prevention effects of brine $\mathrm{pH}$ modification at Hatchobaru power station, Japan. In: Proceedings, International Workshop on Mineral Scaling, May 25-27, Manila, Philippines; 2011.

[30] Guerra CE and Jacobo PE. pH modifications for silica control in geothermal fluids. Presented at short course on geothermal development and geothermal wells. March 11-17, Santa Tecla, El Salvador; 2012.

[31] Tello-López MR, Torres-Rodríguez MA. Acid treatment in wells of the Los Azufres geothermal field to steam production enhancement. In: Proceedings, World Geothermal Congress 2010, April 25-29, Bali, Indonesia; 2010.

[32] Lin C-C, Tsai T-L, Liu W-C, Liu C-C., 2011, Aqueous characteristics and radionuclides in Peito Hot Spring area. Radiat Meas 2011; 46:561-564.

[33] Lin MS, Premuzic ET, Zhoul MS, Johnson SD. Mineral recovery: a promising geothermal power production co-product. GRC Transactions 2001; 25:497-500.

[34] Gallup DL, Featherstone JL, Reverente JP, Messer PH. 1995. Line mine: a process for mitigating injection well damage at the Salton Sea, California (USA) geothermal field. In: Proceedings, World Geothermal Congress; 1995, p. 2406-2412.

[35] Featherstone JL. Process for removing silica from silica-rich geothermal brine. U.S. Patent No. 4,765,913; 1988.

[36] Gallup DL and Featherstone JL. Control of NORM deposition from Salton Sea geothermal brines. GRC Transactions 1993; 17:379-385.

[37] Gunnarsson I, Arnórsson S. Treatment of geothermal waste water to prevent silica scaling. In: Proceedings, World Geothermal Congress, April 24-29, Antalya, Turkey; 2005.

[38] Jackson D, Hill JH. Possibilities for controlling heavy metal sulfides in scale from geothermal brines. Livermore, CA: Lawrence Livermore National Laboratory; 1976. 
[39] Hard RA. Recovering metal values from geothermal brine. U.S. Patent No. 4,602,820. 1986.

[40] Weare JH, Moller NE. Prediction of scaling in geothermal systems. In: Proceedings, Geothermal Program Review VII. DOE Research and Development for the Geothermal Marketplace, March 21-23, San Francisco, CA; 1989.

[41] Tomson MB. Effect of precipitation inhibitors on calcium carbonate scale formation. J Cryst Growth $1983 ; 62: 106-112$.

[42] Wilson JS, King JE, Bullard GR. Study on scale formation and suppression in heatexchanger systems for simulated geothermal brines. Prepared for the U.S. Department of Energy, Geothermal Energy. Freeport, TX: The Dow Chemical Company, Texas Division; 1978.

[43] Rogers LA, Varughese K, Prestwich SM, Waggett GG, Salimi MH, Oddo JE, Street EH, Jr., Tomson MB. Use of inhibitors for scale control in brine-producing gas and oil wells. SPE Production Engineering 1990; 77-82.

[44] Phillips SL, Mathur AK. Methods for geothermal brine treatment. Electric Power Research Institute (EPRI) Research Project 791. Berkeley, CA: Lawrence Berkeley Laboratory, University of California; 1978.

[45] Khoe GH, Emett MT, Robins RG. Photoassisted oxidation of species in solution.

U.S. Patent No. 5, 688,378; 1997.

[46] Gallup DL. Treatment of geothermal waters for production of industrial, agricultural or drinking water. Geothermics 2007; 36:473-483.

[47] Mroczek E, Graham D, Bacon L. The removal of arsenic and silica from geothermal fluids by electrocoagulation. International Mineral Extraction from Geothermal Brines Conference, September 6-8, Tucson, AZ; 2006.

[48] Bacci E, Gaggi C, Lanzillotti E, Ferrozzi S, Valli L. Geothermal power plants at Mt. Amiata (Tuscany-Italy): mercury and hydrogen sulphide deposition revealed by vegetation. 2000; Chemosphere 40:907-911.

[49] Fisher RS. Naturally occurring radioactive materials (NORM) in produced water and scale from Texas oil, gas and geothermal wells: geographic, geologic, and geochemical controls. Austin, TX: Bureau of Economic Geology, The University of Texas at Austin; 1995.

[50] Genter A, Cuenot N, Goerke X, Melchert B, Sanjuan B, Scheiber J. Status of the Soultz geothermal project during exploitation between 2010 and 2012. In: Proceedings, Thirty-seventh Workshop on Geothermal Reservoir Engineering, January 30-February 1, Stanford University, Stanford, CA; 2012.

[51] Yildirim N, Simsek S. Determination of appropriate injection conditions for Kizildere geothermal waste fluid to avoid scale formation and cooling. European Geothermal Conference; 2003. 
[52] NETL (National Energy Technology Laboratory). Produced Water Management Information System, Federal Regulations: U.S. Environmental Protection Agency. Washington, DC: U.S. Department of Energy; 2014.

[53] Tokelove A. The place for computational fluid dynamics models in the optimisation of geothermal cuttings ponds. In: Proceedings, New Zealand Geothermal Workshop, November 19-21, Auckland, New Zealand; 2012.

[54] California Regional Water Quality Control Board (CA RWQCB). Cleanup and abatement order no. R7-2011-0006. California Regional Water Quality Control Board, Colorado River Basin Region. Issued to UNOCAL corporation residue processing facility (GEMCOR), Colorado River Basin Region; 2011.

[55] Moncada-Aguilar A, Ramirez-Hernandez J, Quintero-Nunez M, Avendano-Reyes L. Origin of salinity in groundwater of neighbouring villages of the Cerro Prieto geothermal field. Water Air Soil Pollution 2010; 213:389-400.

[56] Childress AE, Hutton M, Cath T, Walker N, Hen E., 2009, Evaluation of pressure-driven and novel membrane processes for treatment of geothermal brines. GRC Transactions 2009; $33: 711-714$.

[57] Gallup DL. Process for treating sulfide-containing water to reduce sulfide emissions therefrom. U.S. Patent No. 5,028,340; 1991.

[58] Gallup DL, Indra TS. Optimizing cooling water treatment in the tropics. GRC Bulletin 2004; p. 252-258.

[59] EEA (Energy and Environmental Analysis, Inc.). Economic impacts of proposed Montana CBM water management regulations in the Powder River basin. Submitted to State of Montana Board of Environmental Review; 2006.

[60] Wetang'ula GN, Snorrason SS. Geothermal wastewater disposal: chemical stress assessment - Lake Thingvallavatn, Iceland. In: Proceedings, World Geothermal Congress, April 24-29, Antalya, Turkey; 2005.

[61] Zarandi S, Ivarsson G. A review on waste water disposal at the Nesjavellir geothermal power plant. In: Proceedings, World Geothermal Congress, April 25-April 9, Bali, Indonesia; 2010.

[62] Bourcier WL, Lin M, Nix G. Recovery of minerals and metals from geothermal fluid. Presented at the 2003 SME Annual Conference, February 24-26, Cincinnati, OH; 2005.

[63] Bakane P. Overview of extraction of mineral/metals with the help of geothermal fluid. In Proceedings, Thirty-eighth Workshop on Geothermal Reservoir Engineering, February 11-13, Stanford University, Stanford, CA; 2013. 
[64] Lehr L, Allen AD, Lease R. Potential for by-product recovery in geothermal energy operations. Prepared for Geothermal and Hydropower Division, U.S. Department of Energy. Vienna, VA: Energy and Economics Research, Inc.; 1982.

[65] Blake, RL. Extracting minerals from geothermal brines: a literature study. prepared for U.S. Department of the Interior, Bureau of Mines. Twin Cities, MN: Twin Cities Metallurgy Research Center; 1974,

[66] Featherstone, JL, Furmanski G. Process for producing electrolytic manganese dioxide from geothermal brines. U.S. Patent No. 6,682,644; 2004.

[67] Gomez-Zamorano LY, Escalante-Garcia J. Effect of curing temperature on the nonevaporable water in Portland cement blended with geothermal silica waste. Cement Concrete Comp 2010; 32:603-610.

[68] MacKay KD, Rogier ER. Compositions useful in process for extraction of metal values from acidic solutions. U.S. Patent No. 4,128,493; 1978.

[69] Wald M. Start-up in California plans to capture lithium, and market share. New York Times. 2011. http://www.nytimes.com/2011/09/28/business/energy-environment/simbolmaterials-plans-to-extract-lithium-from-geothermal-plants.html?_r=0. Accessed August 8, 2014.

[70] Duyvesteyn, WPC. Recovery of base metals from geothermal brines. Geothermics 1993; 21:773-799.

[71] Harper RT, Thain IA, and Johnson JH. Towards the efficient utilization of geothermal resources. Geothermics 1992; 21(5/6):641-651.

[72] Grimaldi MC, Castrisana WJ, Tolfo FC, Christino FP, Geraldo LML Saliba GC, Lopes DEB. 2010, Produced water reuse for production of chemicals. Society of Petroleum Engineers (SPE) (127174). Presented at the SPE International Conference on Health, Safety, and Environment in Oil and Gas Exploration and Production, April 12-14, Rio de Janeiro, Brazil; 2010.

[73] Gallup D. Geochemistry of geothermal fluids and well scales, and potential for mineral recovery. Ore Geology Reviews 1998; 12:225-226.

[74] Gomez-Zamorano LY, Escalante-Garcia J, Mendoza-Suarez G. Geothermal waste: an alternative replacement material of Portland cement. J Mater Sci 2004; 39: 4021-4023.

[75] Tso B, Jr. Hazardous waste volume reduction: a sulfur sludge dewatering facility at the geysers. GRC Transactions 1990; Vol 14, Part II. August.

[76] Al-Karaghouli A, Kazmerski LL. Energy consumption and water production cost of conventional and renewable-energy-powered desalination processes. Renew Sust Energ Rev $2013 ; 24: 343-356$. 
Table 1

\section{Water treatment technologies for removing total dissolved solids content}

\section{Technology}

Membrane processes

Thermal methods

\author{
Subcategory \\ Reverse osmosis (RO)
}

Electrodialysis and electrodialysis reversal

Forward osmosis

Distillation

Evaporation/

crystallization

Dew evaporation (Dewvaporation)

\section{Advantages}

Mature technology.

Advances have decreased membrane cost and reduced pressure required for practical water fluxes, thus minimizing operational and energy costs. Applicable for highsalinity waters.

Mature technology. Operates at atmospheric pressure. Higher recovery rates than RO. Applicable for salinities up to about $12,000 \mathrm{mg} / \mathrm{L}$ TDS (gives best results with $<3,500$ $\mathrm{mg} / \mathrm{L}$ TDS).

\section{Disadvantages}

High potential for membrane fouling; pretreatment and regular membrane cleaning required. Not typically suitable for very highsalinity water $(>25,000$ $\mathrm{mg} / \mathrm{L})$. Sensitive to fluctuating water quality. Potential for membrane fouling, although less severe than RO (because it is only capable of removing ionic components from solution). Cost is directly proportional to the TDS concentration; competitive with RO at lower TDS concentrations. Limited removal of uncharged constituents.

Uses natural (as opposed to Emerging technology. forced) osmotic pressure difference. Recovery rates can be comparable to RO.

Mature technologies proven in practice. Not influenced by feed-water salt concentration. Capable of processing very highsalinity and variablequality waters. Highquality product water (<10 mg/L TDS).

Capable of processing very high-salinity waters. Can treat to a zero liquid discharge standard.

Heat sources can include combustible fuel, renewables, or waste heat. Capable of processing very high-salinity waters. High recovery rates $(>90 \%)$.
Does not provide highquality water for use in a single step; requires product water to be separated from the osmotic agent.

High energy usage and cost, especially for high recovery rates. Generates concentrated brine that requires separate disposal. Potential for scaling and corrosion; pretreatment commonly required. Sensitive to volatile contaminants.

High energy usage and cost. Potential for scaling. Challenges in disposing of salt residue.

Emerging technology. Energy-intensive if waste heat is not available. Sensitive to atmospheric conditions (e.g., temperature and humidity). 


\begin{tabular}{|c|c|c|c|}
\hline Technology & Subcategory & $\begin{array}{l}\text { Advantages } \\
\text { Lower capital costs than } \\
\text { other thermal methods. }\end{array}$ & Disadvantages \\
\hline Ion exchange & None & $\begin{array}{l}\text { Successfully treats low- to } \\
\text { medium-salinity water. }\end{array}$ & $\begin{array}{l}\text { Large acid usage. Resins } \\
\text { can foul. Challenges in } \\
\text { disposing of rinse water } \\
\text { and spent media (resin). } \\
\text { Ineffective on high-salinity } \\
\text { produced waters. }\end{array}$ \\
\hline Capacitive deionization & None & $\begin{array}{l}\text { Lower capital and energy } \\
\text { costs than RO. Capable of } \\
\text { removing a wide range of } \\
\text { ionic contaminants. High } \\
\text { recovery rates. }\end{array}$ & $\begin{array}{l}\text { Emerging technology. } \\
\text { Limited application } \\
\text { treating low-salinity waters } \\
(<5,000 \mathrm{mg} / \mathrm{L}) \text {. Poor } \\
\text { removal of uncharged } \\
\text { constituents. }\end{array}$ \\
\hline
\end{tabular}

Table 2

Water treatment technologies for addressing noncondensable gases

\section{Constituent(s) of Interest}

Nitrogen, carbon dioxide, methane, argon, and oxygen

Hydrogen sulfide

\author{
Technology \\ Release into the \\ atmosphere \\ Compression and \\ reinjection into \\ the reservoir with \\ the spent geofluid \\ Caustic scrubbing \\ Separation and \\ collection
}

\section{Advantages}

Simple to employ.

Limits GHG emissions.

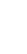

Proven and established method.

Gas can be used on-site or sold in the market as an additional energy and revenue stream.

\section{Disadvantages}

Concerns over greenhouse gas (GHG) emissions (e.g., carbon dioxide) may require limiting emissions in the future.

Results in additional parasitic power consumption.

Must be followed by oxidation, adsorption, and catalytic conversion to elemental sulfur.

Emerging technologies not fully supported in practice.

\section{Table 3} geothermal produced fluid 


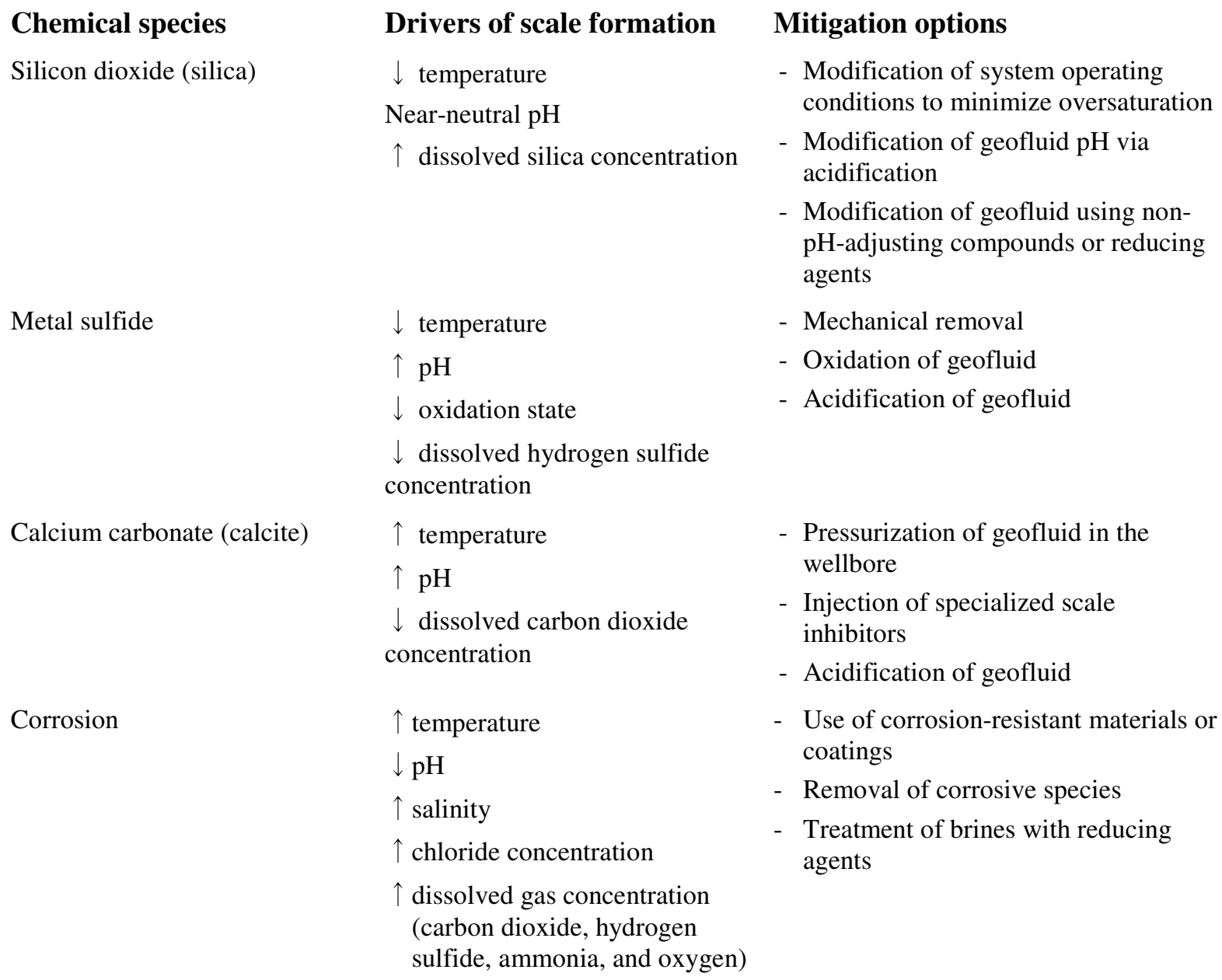

Fig. 1 Geofluid composition box plots for major chemical constituents [2]. 


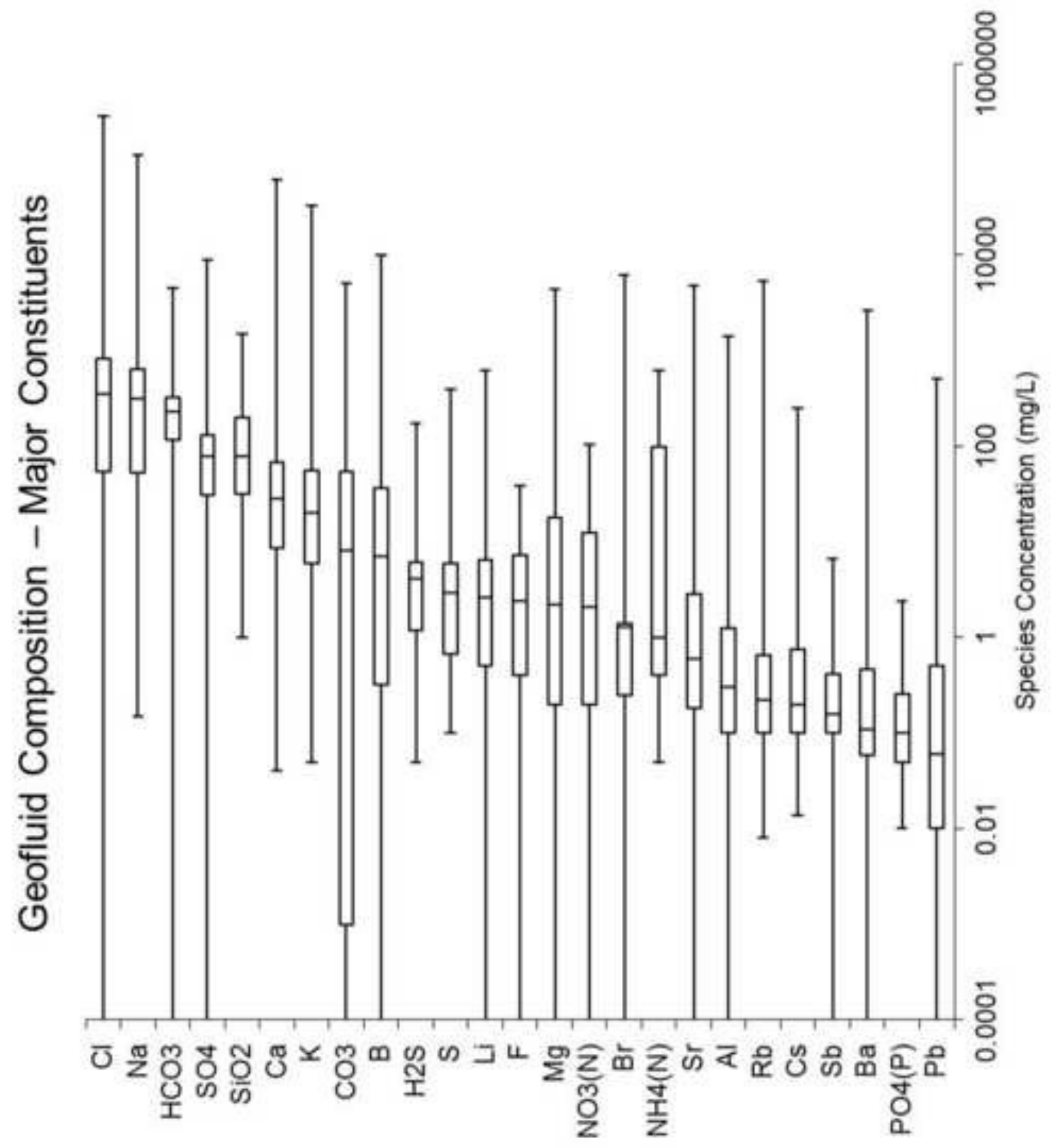

$\frac{\text { 은 }}{\text { 은 }}$ 